\title{
Natural Gas as a Future Fuel for Heavy-Duty Vehicles
}

Wai-Lin Litzke and James Wegrzyn Brookhaven National Laboratory 
SAE routinely stocks printed papers for a period of three years following date of publication. Direct your orders to SAE Customer Sales and Satisfaction Department.

Quantity reprint rates can be obtained from the Customer Sales and Satisfaction Department.

To request permission to reprint a technical paper or permission to use copyrighted SAE publications in other works, contact the SAE Publications Group.

This article was prepared as an account of work sponsored by an agency of the United States

Government. Neither the United States Government nor any agency thereof, nor any of their employees, makes any warranty, express or implied, or assumes any legal liability or responsibility for the accuracy, completeness, or usefulness of any information, apparatus, product, or process disclosed, or represents that its use would not infringe privately owned rights. Reference herein to any specific commercial product, process, or service by trade name, trademark, manufacturer, or otherwise does not necessarily constitute or imply its endorsement, recommendation, or favoring by the United States Government or any agency thereof. The views and opinions of authors expressed herein do not necessarily state or reflect those of the United States Government or any agency thereof.

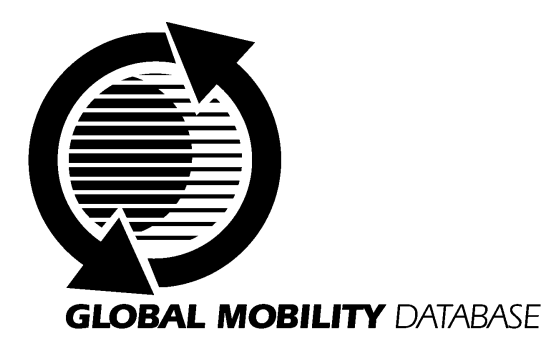

All SAE papers, standards, and selected books are abstracted and indexed in the Global Mobility Database

ISSN 0148-7191

No copyright is asserted in the works of U.S. Government employees.

Positions and opinions advanced in this paper are those of the author(s) and not necessarily those of SAE. The author is solely responsible for the content of the paper. A process is available by which discussions will be printed with the paper if it is published in SAE Transactions. For permission to publish this paper in full or in part, contact the SAE Publications Group.

Persons wishing to submit papers to be considered for presentation or publication through SAE should send the manuscript or a 300 word abstract of a proposed manuscript to: Secretary, Engineering Meetings Board, SAE.

\section{Printed in USA}




\title{
Natural Gas as a Future Fuel for Heavy-Duty Vehicles
}

\author{
Wai-Lin Litzke and James Wegrzyn \\ Brookhaven National Laboratory
}

No copyright is asserted in the works of U.S. Government employees.

\begin{abstract}
In addition to their significant environmental impacts, medium-duty and heavy-duty (HD) vehicles are high volume fuel users. Development of such vehicles, which include transit buses, refuse trucks, and HD Class 6-8 trucks, that are fueled with natural gas is strategic to market introduction of natural gas vehicles (NGV). Over the past five years the Department of Energy's (DOE) Office of Heavy Vehicle Technologies (OHVT) has funded technological developments in NGV systems to support the growth of this sector in the highly competitive transportation market. The goals are to minimize emissions associated with NGV use, to improve on the economies of scale, and to continue supporting the testing and safety assessments of all new systems. This paper provides an overview of the status of major projects under a program supported by DOE/OHVT and managed by Brookhaven National Laboratory. The discussion focuses on the program's technical strategy in meeting specific goals proposed by the NGV industry and the government. Relevant projects include the development of low-cost fuel storage, fueling infrastructure, and HD vehicle applications.
\end{abstract}

\section{INTRODUCTION}

The volume of natural gas consumed by transportation vehicles is projected to rise from five trillion Btu (43 million gasoline equivalent gallons) in 1995 to almost 600 trillion Btu (five billion gallons gasoline equivalent) by 2015. It has been estimated that heavy-duty trucks alone will consume over $50 \%$ of the total natural gas consumed in 2015. Targeting fleet vehicles with high fuel use makes the economics of natural gas utilization most favorable. The combination of fuel cost savings and high fuel usage can justify the incremental vehicle and infrastructure costs. With technological advances and cost reductions, these vehicles can make inroads into the NGV market. As the infrastructure expands and more cost-effective products are offered, penetration of NGVs into other applications will become more viable.
The major hurdles hindering the growth of the natural gas vehicle market are the small size of a refueling and maintenance infrastructure, vehicle cost and driving range, and vehicle markets.

\section{FUEL STORAGE DEVELOPMENT}

For some heavy-duty vehicle applications, such as longhaul trucks, liquefied natural gas (LNG) is the most viable option for long-range use. The amount of fuel that can be stored in a liquefied state with cryogenic tanks greatly exceeds a compressed natural gas system. However, the density of LNG can vary significantly over a range of storage temperatures or saturation pressures. The goal for an LNG vehicle fuel system is to deliver the gas to the engine at the required supply pressure while maximizing the fuel density at the station and vehicle tanks. Figure 1 shows LNG at typical saturation pressures at various distribution points. During offload of LNG from a transport truck to the bulk tank at a fueling station, typical saturation pressures are about 25 psig with a corresponding density of LNG about $3.35 \mathrm{lbs} / \mathrm{gal}$. Therefore, fuel pressure must be raised from 25 psig to about 115 psig at ambient temperature to supply the engine. The majority of LNG vehicles currently use a saturated LNG conditioning system [1]. The most common bulk condition method raises the pressure (without a pump) at the station by warming the fuel. The disadvantage by doing so is that the density is reduced at the higher pressure and therefore less fuel can be delivered to the vehicle tank. With such an arrangement, it has been reported that vehicle range can decrease by about $11 \%$ [1].

An alternative to the above LNG fuel delivery system is one by which a cryogenic pump is used to pump the saturated liquid to the required engine pressure and then vaporized. In such a system the fuel stored at the station or onboard the vehicle can be stored at any pressure, preferably at the lowest possible pressure where the fuel density is at its highest. Under the OHVT program, several projects support the development of this simple concept for HD applications. They include a 


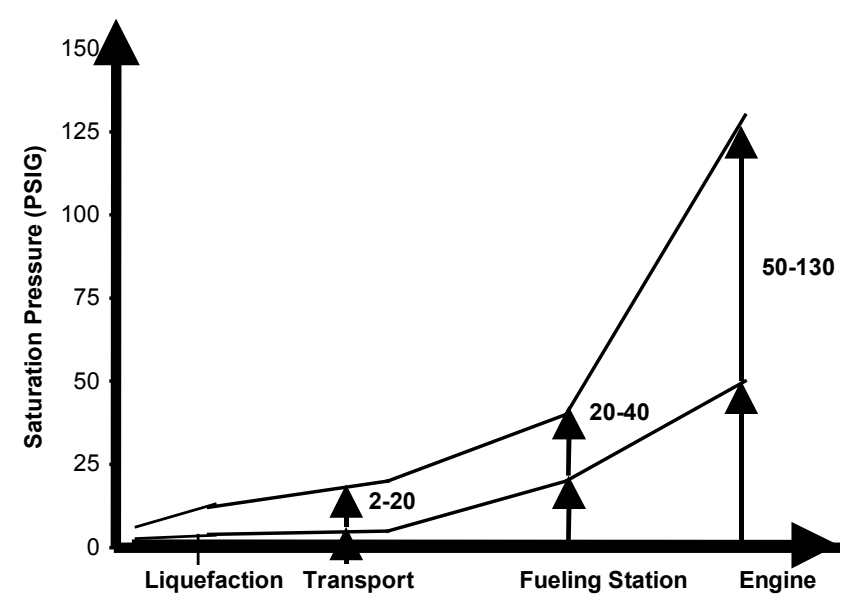

Figure 1. Desired LNG Pressure Ranges, Source[2]

low-cost, low-pressure vehicle tank and onboard cryogenic pump. The following details the current status of component development.

STORAGE TANKS - On-board fuel storage is the most expensive item contributing to the high incremental cost of a natural gas vehicle. Industry goals are to reduce these costs $50 \%$ by 2010 . The specific cost goals for 5 and 10 years, which were developed by the NGV industry and adopted by DOE, are $\$ 70 /$ dge (diesel gallon equivalent) and $\$ 37 / \mathrm{dge}$, respectively. These costs would be a significant reduction from the current cost for fuel tanks, which is approximately $\$ 140 /$ dge. DOE is funding Cryogenic Fuels and Technifab Products to fabricate and conduct performance tests on their LNG tanks that incorporate different insulation materials and configurations. Instrumentation, fuel conditioning systems and manufacturing methods will be evaluated to minimize tank production costs. The goal is to be able to manufacture 1000 tanks per year at a cost of $\$ 90 / \mathrm{dge}$, or just over $\$ 6000$ per tank. This patented design has already been tested in a low-pressure (70 psig), threetank system for LNG transit buses. For the same driving range, this entire system is lighter and costs about $40 \%$ less than other LNG systems currently available on the market. With their continued on-road evaluation of these tank systems, and further testing at higher pressures (110 psig) for current applications, it is projected that they will be ready for mass-production and sale within two years.

ONBOARD FUEL DELIVERY - For LNG heavy-duty vehicles, it is most advantageous to have a pumped fuel delivery system whereby the vehicle tank can be maintained at low saturation pressures. In such a system, liquefied natural gas can be stored at the highest densities to maximize driving range. The primary purpose of the pump is to supply those engines with medium to high-pressure requirements (150 -3600 psig). The high-pressure requirement supports current development efforts in the efficient, high-pressure direct injection (HPDI) engines.

Under the OHVT program, Beck Engineering has been developing a magnetically driven, free-piston pump. The main advantage that this pump design offers over existing cryogenic pumps is its use of non-contacting fluid film bearings for improved durability. Laboratory benchscale tests conducted to date have shown that the pump can meet fuel flow and pressure requirements at above 120 psig. Continued testing is being done that involves integrating the pump with a direct-injected natural gas engine developed by Mack Trucks. The goals are to maximize the pump's efficiency and to minimize costs associated with production; it has been estimated that the pump may be sold for less than $\$ 1000$.

\section{FUEL INFRASTRUCTURE}

One way to penetrate the transportation market is to develop a source of low-cost natural gas. OHVT is supporting the development of technologies that will enable increased consumption of natural gas from unconventional, economical sources. Among the unconventional sources that could be exploited is landfill gas. As shown in Table 1, landfill gas consists of approximately $50 \%$ methane, $50 \%$ carbon dioxide, small amounts of water vapor, volatile organic compounds, and other contaminants. Transforming landfill gas into natural gas involves extracting methane from the other components. Large landfill sites typically are candidates for energy recovery projects. A combined system of purification and liquefaction is needed to produce $100 \%$ methane for liquefied natural gas applications.

\begin{tabular}{|l|c|}
\hline \multicolumn{2}{|c|}{ Landfill Gas Properties } \\
\hline & \\
Temperature, ${ }^{\circ} \mathrm{F}$ & 70 \\
Pressure, psia & 14.7 \\
Methane & $50-55 \%$ \\
Carbon Dioxide & $40-45 \%$ \\
Nitrogen & $0-5 \%$ \\
Contaminants & $0.001-0.1 \%$ \\
Water & saturated \\
\hline
\end{tabular}

Table 1. Properties of landfill gas

LANDFILL GAS TO LNG - Major factors that affect the feasibility of producing LNG from landfill gas include the scale of methane production at the site, the cost of other competing landfill methane-to-energy projects, and the cost of small-scale purification and liquefaction systems. In order for such a system to be cost-effective, its scale must be large enough to recover the capital investment, operating costs, and the loss of profit from other energy projects. Companies developing such technologies suggest that these projects become cost-effective at a production rate of 15,000 gallons of LNG per day, which 
would require about 3 million standard cubic feet of landfill gas per day [3]. This volume of fuel could serve a fleet of 120 vehicles. For one project, it was estimated that the cost to produce $L N G$ at this capacity would be about $\$ 0.40$ per gallon [3]. This includes the capital cost, operations \& maintenance, the cost of input gas, and some minimal transportation cost. Transportation of the fuel to a distant market adds to the cost of the fuel considerably; using some of the fuel for refuse trucks that are located at the landfill site improves the overall economics. Entry into this niche market of fleet vehicles can effectively demonstrate the technology, gather experience, and lead to wider consumer acceptance.

A market study done for the Gas Technology Institute (GTI) indicates that small-scale liquefaction is feasible in the 5000-10,000 gal/ day production range with a commercial unit costing less than $\$ 500,000$ [4]. With OHVT support, Gas Technology Institute has developed a single-stage, mixed refrigerant, natural gas liquefier that is portable and low-cost for the transportation and other non-utility markets. This prototype unit which has a capacity of up to $2000 \mathrm{gal} / \mathrm{day}$ can be scaled to match feedstock flow and composition characteristics. A gas purification system is currently being designed for integration with the liquefier unit for the processing of pipeline quality feedstock, which does not have all contaminants found in landfill gas. This system is scheduled to be completed by the end of year 2001. The capital equipment cost for this system is estimated to be $\$ 350,000$ with energy costs to operate the unit at about $\$ .10 /$ gal. The design is being optimized for efficiency, operation and reliability. Additional costs associated with purification of trace contaminants for landfill gas applications will undoubtedly increase this capital cost.

LANDFILL GAS PURIFICATION - In order to be able to use landfill gas (LFG) for natural gas vehicle applications or even for power generation (which traditionally is provided by pipeline gas), high-purity methane must be removed from the other components of the LFG. As carbon dioxide $\left(\mathrm{CO}_{2}\right)$ is a major component of the LFG, it has been proposed that the purification and liquefaction of $\mathrm{CO}_{2}$ into a saleable product would improve the economics of developing LFG for LNG. These processes would be integrated such that both products would be produced simultaneously. Under the OHVT program, DOE has funded Acrion Technologies to conduct a feasibility study on producing $L N G$ and liquid carbon dioxide $\left(\mathrm{LCO}_{2}\right)$ from landfill gas. Using their patented, adsorption process, which uses liquid $\mathrm{CO}_{2}$ produced insitu, they can recover more than $99 \%$ of the methane as usable product. More than $80 \%$ of the liquid $\mathrm{CO}_{2}$ can be retained as the secondary product. A pilot-scale system has already been successfully demonstrated. Using landfill gas properties as shown in Table 2 as the design basis, the characteristics of the end products are shown in Table 3. The purified natural gas in the end product meets the criteria for pipeline methane gas. This study concluded that the project is economically feasible for a modest size landfill that produces 4 million standard cubic feet per day (MMSCFD) of LFG to make 19,000 gallons of LNG per day and 66 tons of liquid $\mathrm{CO}_{2}$. The suitability of the project depends on the availability of a market that is close to this source of production. The product scenarios include pipeline gas/liquid $\mathrm{CO}_{2}$, LNG/ liquid $\mathrm{CO}_{2}$, and methanol, in order of increasing capital investment. With a capital investment of the plant of $\$ 5.3$ million and annual operating costs of $\$ 1.0$ million, the simple payback is a little over 3 years with a methane selling price of $\$ 2.00 / \mathrm{MMBtu}$ (million Btu) and liquid $\mathrm{CO}_{2}$ at $\$ 40 /$ ton [5].

\begin{tabular}{|l|l|}
\hline \multicolumn{2}{|c|}{$\begin{array}{c}\text { Conversion of LFG } \\
\text { Design Basis }\end{array}$} \\
\hline $\begin{array}{l}\text { Landfill Gas Flow } \\
\text { (LFG) }\end{array}$ & $\begin{array}{l}4 \text { MMSCFD } \\
(439 \mathrm{lb}-\mathrm{mole} / \mathrm{hr}, \text { dry })\end{array}$ \\
$\begin{array}{l}\text { LFG pressure } \\
\text { LFG Composition } \\
\text { (dry basis) }\end{array}$ & 14.7 psia \\
& $\begin{array}{l}54 \% \text { Methane } \\
45 \% \text { Carbon Dioxide } \\
1 \% \text { Nitrogen } \\
\text { Trace contaminants } \\
\text { Water dew point } 70^{\circ} \mathrm{F}\end{array}$ \\
\hline
\end{tabular}

Table 2. Processing Landfill Gas- Design Basis.

\begin{tabular}{|l|c|c|}
\hline \multicolumn{3}{|c|}{ Product Characterization } \\
\hline Flow & $\begin{array}{c}\text { Pipeline Natural Gas } \\
2.25 \mathrm{MMSCFD}\end{array}$ & $\begin{array}{c}\text { Liquid } \mathrm{CO}_{2} \\
88.3 \mathrm{tons} / \mathrm{day}\end{array}$ \\
& $247 \mathrm{lb}-\mathrm{mol} / \mathrm{hr}$ & $167.2 \mathrm{lb}-\mathrm{mol} / \mathrm{hr}$ \\
Pressure & $485 \mathrm{psia}$ & $\mathrm{psia}$ \\
Temperature & -- & $-1.4^{\circ} \mathrm{F}$ \\
& & \\
Composition & & $1 \mathrm{ppm}$ \\
Methane & $96 \%$ & $99.99 \%$ \\
Carbon dioxide & $2.2 \%$ & --- \\
Nitrogen & $1.8 \%$ & --- \\
Btu/SCF & 960 & liquid \\
Phase & gas &
\end{tabular}

Table 3. End-products characterization.

Acrion Technologies is currently exploring the potential for a natural gas recovery project at several municipal landfill sites. One site of interest includes the Arden Landfill site located in Washington, PA which has been operating seven heavy-duty LNG refuse trucks (Mack Trucks with E7G engines) since August 1997. This project which was evaluated under a collaboration between DOE, National Renewable Energy Laboratory, and Battelle [6], is briefly described in the following section on LNG application. 


\section{LNG HEAVY-DUTY VEHICLE APPLICATION}

Although the natural gas industry supports development of vehicles in all class sizes, applications, and markets, the highest priority is high fuel-use applications, especially medium-duty and heavy-duty vehicles. The overall economic and environmental impacts from natural gas use in these vehicles are potentially the greatest. Realization of this potential depends on vehicle performance and costs.

In conjunction with methane production from landfill gas, one obvious application for natural gas use is for refuse trucks. In 1991, Waste Management Inc. (formerly Chambers Development Company) began evaluating the Arden Landfill site located in Washington, PA, as a possible source of natural gas as an alternative fuel for its own vehicles. However, cost-effective technology to produce a clean fuel for vehicle engines was not available at that time. Nevertheless, the effort to find an alternative fuel to displace the diesel trucks ensued. This led to an LNG truck development effort and the construction of an on-site LNG fueling station that was funded by government and industry participants. With the introduction of its first truck in 1997 and six additional trucks thereafter until 1997, NREL and Battelle have been evaluating their performance and comparing the data with the diesel trucks in operation [6].

In general, the LNG trucks met the operating requirements with lower emissions for particulate matter, non-methane hydrocarbon emissions and nitrogen oxides compared to the diesel trucks [6]. However, the LNG trucks cost significantly more to operate due to the high cost of fuel which had to be transported onto the site. During the data collection and evaluation phase, Waste Management paid $\$ 0.88$ per LNG gallon, which is considered very high compared to the retail prices quoted by other LNG sources ( $\$ 0.45-\$ 0.50 / L N G$ gallon). As a result there have been no recent plans to purchase more LNG trucks. To date, there is still an interest to pursue the purification and liquefaction of the site's landfill gas. With their adequate production rate of landfill gas, it is feasible to produce LNG at well within this quoted price range using the purification and liquefaction process described in the previous section. The major considerations include the scale of production and the availability of a local secondary market for the highly pure liquid carbon dioxide. These project considerations are still underway.

\section{CONCLUSION}

Although the introduction of many alternative fueled vehicles have been driven by the environmental movement and national security policies, the market sustainability of natural gas vehicles depends on the industry's ability to provide the products at a reasonable cost. A developed infrastructure is needed to readily provide the fuel for an adequate driving range. This paper summarized some of the recent technology developments that can provide low-cost fuels from unconventional sources of methane, and vehicle product improvements to meet these goals. It also presented a feasible scenario for the production of LNG from landfill gas and on-site use in refuse vehicles. Entry into a niche market encompassing heavy-duty, fleet vehicles and public access fueling stations is a means to expand natural gas use.

\section{ACKNOWLEDGMENTS}

This work was done with support from the U.S. Department of Energy, Office of Heavy Vehicle Technologies under contract no. DE-AC02-98CH10886.

\section{REFERENCES}

1. Weins, J., Powars, C. and Pope, G., "LNG Vehicle Fuel Pressure Strategy Alternatives," SAE Fuels and Lubes Meeting, Coral Gables, FL, April 12-14, 2001, SAE Paper No. 2001-01-1919.

2. Watkins, R., "DART LNG Program- Facilities 2001 Status," presented to Dallas Area Rapic Transit-LNG Users Group Meeting, February 9, 2001, Dallas, TX.

3. Hiester, T., "The Road to Cost Effective LNG," presented at Natural Gas Vehicle Coalition Conference and Exhibition, Las Vegas, NV, September 17, 2000.

4. "LPMRC Liquefier Market Assessment," prepared for Gas Research Institute by Zeus Corp., March 2000, Contract No. 8022.

5. Brown, W., Cook, W.J., Siwajek, L. and Neyman, M., "Landfill Gas Conversion to LNG and LCO2," Phase II Report, Acrion Technologies, October 2000, DOE Contract No. DE-AC02-99CH10982.

6. 'Waste Management's LNG Truck Fleet Final Data Report: DOE/NREL Alternative Fuel Truck Evaluation Project, prepared for National Renewable Energy Laboratory by Battelle, August 2000. 